\title{
Libre comercio y gobernanza del medio ambiente en México: ¿complementariedad o contradicción?*
}

DOI: $10.32870 /$ mycp.v14i40.362

Delphine Rabet ${ }^{1}$

\section{Resumen}

$\mathrm{E}$ n este artículo se analizan los puntos de tensión existentes entre la regulación del medio ambiente por parte del Estado mexicano y el proceso de liberación económica de México. El análisis argumenta que como consecuencia de la integración económica de Norteamérica, las instituciones mexicanas están estableciendo normas y valores que estructuralmente dan prioridad a los intereses de los inversionistas extranjeros sobre el bienestar ambiental y social de México. Asimismo, en el artículo también se subraya la manera en cómo este proceso afecta a la soberanía mexicana en el sector ambiental. Finalmente y de manera más general, se explora la contradicción inherente que existe entre el régimen de libre comercio y el régimen ambiental de la gobernanza global.

Palabras clave: México, TLCAN, inversión extranjera directa, medio ambiente.

\section{Introducción}

Durante los últimos 20 años México tomó el camino de la liberalización económica, experimentó un aumento dramático de la inversión extranjera

* Artículo recibido el 28 de abril de 2010 y dictaminado el 27 de julio de 2010.

1. PhD Candidate of the University of Sydney, Department of Government and International Relations. E-mail: Delphine.rabet@sydney.edu.au 
directa y adoptó un modelo económico orientado a la exportación (Dussel Peters, 2008). En el mismo periodo la preservación del medio ambiente fue reconocida por el gobierno como una responsabilidad del Estado mexicano y como una problemática a solucionar, volviéndose, de esta manera, en una cuestión política (Mumme y Lybecker, 2002). La simultaneidad de estos dos procesos sin duda merece más atención. En este artículo se pretende analizar los puntos de tensión existentes entre la liberalización de la economía mexicana y el grado de autonomía que tiene el Estado mexicano para la regulación del medio ambiente. El análisis argumenta que como consecuencia de la integración económica de Norteamérica, las instituciones mexicanas están estableciendo normas y valores que estructuralmente dan prioridad a los intereses de los inversionistas extranjeros sobre el bienestar ambiental y social de México. Asimismo, también se enfatiza la manera en cómo este proceso afecta a la soberanía mexicana en el sector ambiental. Finalmente, y de manera más general, se explora la contradicción inherente que existe entre el régimen de libre comercio y el régimen ambiental de la gobernanza global.

En una primera instancia, es necesario entender cómo la transformación de la economía mexicana afectó el desarrollo de un régimen ambiental en México. Las empresas multinacionales (MNC), portadoras principales de la inversión extranjera directa (IED), se convirtieron en actores importantes para las actividades económicas de México (Dussel Peters, 2008), una de las economías más abiertas del mundo (Ibarra Colado, 2006). La mayoría de estas MNC tienen sus oficinas centrales en Estados Unidos (Waldkirch, 2008), país con el cual México firmó el Tratado de Libre Comercio de América del Norte (TLCAN) en 1994. ${ }^{2}$ Los intereses corporativos estadounidenses se han convertido, por lo tanto, en un componente integral del paisaje económico mexicano. Es importante señalar que, si bien el gobierno estadounidense tenía en mente la protección de los intereses de su sector comercial en la negociación del TLCAN, también se aseguró de incluir algunas consideraciones ambientales en el mismo, así como en uno de sus acuerdos adjuntos. El TLCAN representa, para algunos expertos en el área, el tratado comercial más progresivo ambientalmente (Gilbreath, 2003; Kirton y MacLaren, 2002; Wisner y Epstein, 2005).

La falta de compromiso estadounidense en las cuestiones ambientales globales (Falkner, 2005) aparece como una contradicción con este énfasis de

2. Canadá es el tercer país signatario del tratado. 
Washington en promover la inclusión de medidas de protección ambiental en el TLCAN, asegurándose, de esta manera, del compromiso del gobierno mexicano por cumplir las medidas establecidas en el tratado y por mejorar el récord ambiental nacional. A primera vista, los intereses corporativos estadounidenses parecen haber sido sometidos a favor de principios ambientales en la negociación del TLCAN, al menos en razón de lo plasmado en el texto del acuerdo, lo cual es una estrategia política extraña de Estados Unidos. Al mismo tiempo, el hecho de que las cuestiones ambientales son definidas y cuestionadas directa e indirectamente por los mecanismos del TLCAN también es

La falta de compromiso estadounidense en las cuestiones ambientales globales aparece como una contradicción con este énfasis de Washington en promover la inclusión de medidas de protección ambiental en el TLCAN causa de cuestionamientos sobre el grado de autonomía que el Estado mexicano ostenta para regular el medio ambiente a nivel nacional. En este artículo se pretende arrojar luz sobre la dinámica de poder relacionada con el fenómeno de la IED en México que puede explicar este desarrollo.

En la siguiente sección se explica la evolución de la IED y de la regulación ambiental en México. En seguida serán discutidas las instituciones ambientales específicas creadas por el TLCAN, lo que dará paso a un análisis de la protección de los inversionistas extranjeros garantizada por el tratado. Finalmente, en la última parte se destacan las contradicciones que existen entre el régimen de libre comercio y el régimen ambiental, como lo ilustra el caso de México. Esto también revelará el impacto indirecto de la IED sobre el Estado mexicano en términos de su capacidad (reducida) para regular el medio ambiente.

\section{Liberalización económica y el despertar ambiental en México}

\section{Del proteccionismo a la liberalización}

México tuvo una relación turbulenta con los extranjeros a lo largo de su historia, en particular con los inversionistas extranjeros. Desde su independencia 
en 1821, México pasó por invasiones reiterativas de otros Estados y actores privados que obstaculizaron su soberanía nacional y su habilidad para manejar su economía y asuntos internos (Cockroft, 1983). Una fuerte respuesta - todavía objeto de orgullo nacional- a la invasión de intereses extranjeros en la economía mexicana, ha sido la expropiación en 1938 de los activos de casi todas las compañías petroleras extranjeras (en su mayoría inglesas y estadounidenses) que operaban en el territorio mexicano (Knight, 1992). Con esta decisión, el presidente Lázaro Cárdenas siguió literalmente el artículo 27 de la Constitución mexicana que declara que el subsuelo y cualquier recurso natural descubierto en el nivel subsuelo es propiedad del Estado mexicano. Sin sorpresa, esta decisión desanimó a los inversionistas extranjeros a hacer negocios en México.

Además, durante las décadas siguientes el modelo económico de industrialización de sustitución de importaciones (ISI) llevó al Estado a subvencionar la industria mexicana, a crear varias compañías nacionales, a mantener precios altos "artificiales" para los bienes mexicanos y a restringir fuertemente las importaciones, así como la inversión extranjera directa (Otero, 1995). Hay cierto consenso, entre algunos académicos, acerca de que durante este periodo la economía mexicana prosperó y consiguió niveles satisfactorios de desarrollo económico (Babb, 2001; Moreno-Brid, et al., 2005; Rodrik, 1992). Asimismo, los inversionistas extranjeros tenían menos poder y las posibilidades de inversión eran limitadas debido a una reglamentación estatal estricta (Dussel Peters, 2000) y a la carencia de acuerdos internacionales que protegieran sus intereses. El Estado mexicano había asegurado que tenía la autonomía para decidir su propia política económica nacional con poca interferencia de actores extranjeros. A partir de finales de la década de 1930 hasta finales de la de 1970, bajo ISI, México siguió su desarrollo económico con inversiones extranjeras restringidas. No obstante, en tiempos más recientes, atraer y retener la inversión extranjera en el país se ha convertido en un elemento principal de la política económica mexicana.

El periodo de ISI terminó con la crisis financiera de 1982, que condujo al presidente Miguel de la Madrid a anunciar una moratoria sobre la deuda externa mexicana (Looney, 1985). México había comenzado ya a liberalizar tímidamente su economía a finales de la década de 1970, y la crisis de 1982 funcionó como un incentivo adicional fuerte para cambiar a un modelo económico diferente (Roett y Paz, 1995). Además, este modelo nuevo fue apoyado por una generación de políticos influyentes y más joven dentro del 
aparato estatal, la mayoría de quienes fueron educados profesionalmente en universidades estadounidenses (Babb, 2001) y estaban convencidos ideológicamente de los beneficios de adoptar principios económicos más liberales.

Si bajo el modelo de ISI el Estado desempeñó un papel fundamental sobre las decisiones de inversión, las reformas conducidas por gobiernos sucesivos en la década de 1980 cambiaron este rol y favorecieron la inversión privada doméstica y extranjera. Al mismo tiempo, el Estado trató de orientar la inversión más hacia las exportaciones y actividades comerciales (Máttar, et al., 2002). Concretamente, estas reformas incluyeron la privatización de la mayoría de las industrias estatales, un cambio de política en cuanto a la IED, la disminución progresiva de las barreras comerciales proteccionistas y la revisión de la Constitución mexicana para asegurar los derechos de propiedad de los inversionistas extranjeros en el país (Babb, 2001). En 1984 y 1989, nuevas enmiendas a la Ley para la Promoción y la Regulación de la Inversión Extranjera (1973) hicieron posible para el inversionista extranjero invertir en sectores previamente protegidos (Dussel Peters, 2000).

La expectativa de firmar un tratado comercial con Estados Unidos tuvo un papel crucial en la reforma de la IED en México. La nueva Ley de Inversiones Extranjeras de 1993 representó una verdadera oportunidad para los inversionistas, ya que permitió IED en casi todas las actividades económicas de México (Dussel Peters, 1996). En 1992 el presidente Carlos Salinas de Gortari procedió a una revisión de la Constitución mexicana, en particular del artículo 27, permitiendo a inversionistas extranjeros el derecho de adquirir tierra - antes colectivamente otorgado especialmente a comunidades indígenas - e incrementando el nivel de protección legal para los inversionistas extranjeros (Jones y Ward, 1998). Estas medidas prepararon el terreno para la firma del TLCAN, el cual iba a asegurar la supresión definitiva de la mayoría de las barreras comerciales entre México, Canadá y Estados Unidos. El TLCAN implicaba no sólo el libre comercio, sino también reglas sobre la inversión extranjera directa, el tratamiento de las empresas extranjeras, y los derechos sobre la propiedad intelectual (Chase, 2003).

\section{La IED en México pos-TLCAN}

La liberalización de la economía mexicana se aceleró a partir de la década de 1980, resultando en el acceso de México al GATT en 1986. Sin embargo, cuando el TLCAN entra en vigor en 1994, es que la IED se hace cada vez más 
central para el desarrollo del sistema económico mexicano moderno (Waldkirsh, 2008). En el periodo 1994-2000 la IED total se cuadruplicó en México (Camp, 2007). Las exportaciones también experimentaron un crecimiento: entre 1985 y 2000 aumentaron de 19 mil millones de dólares a 166 mil millones (UNCTAD, 2002). Así, con el TLCAN México estableció condiciones excesivamente favorables para los inversionistas extranjeros.

El TLCAN relacionó el desarrollo económico de México con Estados Unidos, puesto que más de 65\% del total de IED provino de ese país entre 1994 y 2006 (Dussel Peters, 2008) y cerca de 90\% se concentró en el sector de manufactura para la exportación (Dussel Peters, 2008). Cualitativamente, la IED se encuentra concentrada en sectores industriales particulares, como por ejemplo la industria automotriz, la alimentaria, la farmacéutica y la química (Máttar, et al., 2002; Morales, 1999) y en un pequeño número de firmas extranjeras. Aproximadamente 3\% de las MNC representan más de 75\% de la IED total en México y esta concentración sigue aumentando rápidamente (Dussel Peters, 2008). Así, pocas empresas extranjeras grandes, la mayoría estadounidenses, aparecen como los actores principales para la IED en México. La liberalización de la economía mexicana ha transformado, por lo tanto, no sólo la manera en que México genera su riqueza, sino también los términos de su relación con su poderoso vecino.

Las consecuencias económicas de la liberalización de la economía mexicana van más allá del alcance de este artículo. En cambio, éste ofrece una perspectiva ambiental acerca de los límites y de las oportunidades que ofrece la IED en México. La implementación del régimen de libre comercio entre México y Estados Unidos ocurrió al mismo tiempo que el desarrollo al nivel global y nacional de las nuevas reglas de gobernanza ambiental, el próximo tema a analizar.

\section{Ecología en México}

Si la década de 1970 había anunciado grandes transformaciones económicas en la economía política mexicana, también introdujo los primeros pasos de México en lo que se transformaría en un marco regulador nacional, diseñado específicamente para incluir una amplia variedad de cuestiones ambientales. El desarrollo de un régimen ambiental global, el activismo de organizaciones no gubernamentales (ONG) domésticas e internacionales y, especialmente importante para la presente discusión, la inclusión de cláusulas ambientales 
en la mayoría de los tratados comerciales internacionales, influyeron fuertemente en la formación del marco regulador mexicano.

En 1972 México adoptó su primera ley ambiental general, ligeramente modelada a imagen del Acta Ambiental Nacional estadounidense (NEPA por sus siglas en inglés). Esto reflejó el primer signo de consenso global sobre la crisis del medio ambiente, discutido el mismo año en la Conferencia de Estocolmo organizada por las Naciones Unidas (Mumme y Lybecker, 2002). En la década de 1970 las ideas ecológicas de intelectuales europeos comenzaron a circular en la sociedad civil en México (Quadri de la Torre, 1990); durante la década de 1980, la colaboración de grupos ambientales domésticos y extranjeros creó una comunidad de organizaciones no gubernamentales activa y diversa (García Johnson, 2000). Comenzando en 1983, pero sobre todo desde finales de la década de 1980, México amplió sus lazos internacionales, firmando varios acuerdos importantes y estableciendo otras relaciones multilaterales que han profundizado su compromiso hacia la protección del medio ambiente (Gallagher, 2004).

Un paso importante se dio en 1988, cuando los esfuerzos de México para regular la esfera ambiental se hicieron más formales con una revisión completa de la Ley Ambiental Nacional, sustituyendo la vieja ley por una nueva Ley General de Equilibrio Ecológico y Protección del Medio Ambiente (LGEEPA). Hasta ahora esta legislación constituye el marco conforme al cual se promulga la reglamentación ambiental y se coordinan las actividades de agencias estatales (Gallagher, 2004). Esta ley tiene por base el principio de que todos los mexicanos comparten los ecosistemas nacionales —enfatiza la participación de la comunidad, sugiere que la protección del medio ambiente debiera privilegiarse por sobre los derechos a la propiedad, y adopta el argumento: "el que contamina, paga" (García Johnson, 2000)—. Estos principios implican que las preocupaciones ambientales deberían reemplazar en la práctica a las consideraciones económicas.

Es importante mencionar otras iniciativas. En 1996 una nueva legislación aumentó la capacidad financiera y la autonomía de los gobiernos locales y estatales para la planificación ambiental y para asegurar el cumplimiento de la reglamentación (Gilbreath, 2003). Esta legislación es significativa porque la centralización del gobierno mexicano y la carencia de recursos y de autonomía de las administraciones municipales fueron identificadas como unas de las razones de la ineficiencia para confrontar los problemas ambientales (Mumme y Lybecker, 2002). Además, en 1998 el Congreso mexicano también 
aprobó una enmienda constitucional que garantiza a todos los ciudadanos el derecho a un medio ambiente apropiado y sano (Gilbreath, 2003). Estas decisiones estatales son de suma importancia y serán retomadas más adelante en la discusión, al compararlas con los derechos de los inversionistas extranjeros en el país.

\section{Tratado de Libre Comercio y el medio ambiente}

Si el régimen ambiental global había influenciado para el establecimiento de una reglamentación ambiental más rigurosa, la anticipación de la firma del TLCAN motivó aún más la inclusión de la política ambiental en los esfuerzos del gobierno mexicano (Gilbreath, 2003). Así, en 1992 México estableció una nueva oficina para asuntos relacionados con el cumplimiento de la ley ambiental: la Procuraduría Federal de Protección al Ambiente (Profepa). Este organismo es responsable, por ejemplo, de inspeccionar plantas para determinar si cumplen con los estándares legales de emisión de gases contaminantes (Gallagher, 2004). De igual manera, entre 1992 y 1994 México implementó nuevas leyes federales para la regulación de temas relacionados con la biodiversidad, con procesos de estandarización y con la reducción del nivel de contaminación del agua, por mencionar algunas iniciativas. Más aún, en 1994 la Secretaría de Medio Ambiente, Recursos Naturales y Pesquería (Semarnap) fue nombrada la encargada de supervisar el cumplimiento de la ley ambiental (Álvarez-Larrauri y Fogel, 2008), sustituyendo a la Secretaria de Pesca.

Tanto la reforma administrativa de 1992, como los acuerdos ambientales adicionales del TLCAN reflejan la voluntad del gobierno mexicano de satisfacer o tranquilizar a los miembros del Congreso estadounidense críticos de la propuesta del TLCAN (Mumme, 1994). De hecho, los debates políticos registrados en Estados Unidos tuvieron una fuerte influencia, aunque indirecta, en el diseño del marco institucional del gobierno mexicano para la protección del medio ambiente. Muchos miembros del Congreso estadounidense tuvieron que enfrentar a su base electoral sobre la pérdida de empleos, como una de las consecuencias potenciales del TLCAN, así como sobre la posibilidad del traslado de compañías estadounidenses a México, donde la reglamentación ambiental más laxa era vista como una de las ventajas para trasladar sus operaciones a este país (Cameron y Tomlin, 2000). México trató de responder a esta crítica con las reformas y la creación de las nuevas legislaciones previamente mencio- 
nadas, como prueba de su buena voluntad y firme compromiso de establecer una reglamentación ambiental más fuerte y estricta (García Johnson, 2000).

En un periodo muy corto México desarrolló una reglamentación ambiental e instituciones ad hoc nuevas de manera coherente, y potencialmente con un gran alcance. La presión de la sociedad civil, con el apoyo de grupos ecologistas estadounidenses, un régimen ambiental internacional más desarrollado, la experiencia de la firma de tratados comerciales con otros países y la buena voluntad del gobierno mexicano de mejorar su récord ambiental, aunque haya sido motivado por cuestiones políticas, se erigen como los factores que contribuyeron a la evolución del marco de regulación ambiental en México. Con una Secretaría del Medio Ambiente (Semarnat), una Procuraduría Federal de Protección al Ambiente (Profepa), el Instituto Nacional de Ecología (INE), y una serie completa de leyes ambientales, en la actualidad México parece estar mejor equipado para lidiar con cuestiones ambientales que muchos de los países desarrollados.

Sin embargo, México también tiene unas restricciones severas en términos de los recursos financieros disponibles para asegurar el óptimo funcionamiento de estas instituciones y, consecuentemente, el respeto y la implementación de la reglamentación ambiental. Como ya se mencionó anteriormente, México diseñó reglas más rigurosas y aparentemente creó un marco adecuado para abordar cuestiones ambientales, entre otros motivos, como una reacción a preocupaciones del Congreso estadounidense. Sin embargo, la influencia estadounidense en el tema no paró allí, sino que, como se demuestra en la siguiente sección, los principios ambientales fueron integrados directamente en las negociaciones del TLCAN a través de un acuerdo específico.

\section{TLCAN y las consideraciones ambientales}

Medio ambiente y libre comercio

Desde el principio de la década de 1990, los debates sobre las posibles consecuencias económicas y ambientales del TLCAN fueron frecuentes e implacables tanto en Estados Unidos como en México (Stern, 2005). Durante las negociaciones el medio ambiente se convirtió rápidamente en un asunto político. El gobierno estadounidense esperaba incluir cláusulas ambientales en el tratado con el fin de satisfacer al Congreso - preocupado por la pérdida de empleos con el traslado de industrias a territorio mexicano- y a los 
activistas ambientales, mientras que el sector privado se oponía fuertemente a su inclusión (Box-Steffensmeier, et al., 1997). Esto último, ya que la mayoría de las empresas estadounidenses grandes estaban generalmente a favor del TLCAN; no obstante, se mostraban renuentes a aceptar las restricciones ambientales (Mumme, 1994), considerando, así, que esta cuestión debía ser negociada por separado del tratado.

En 1993 la discusión tomó un giro económico y las opiniones se concentraron en los argumentos de dos académicos prominentes, quienes sostenían perspectivas opuestas sobre las posibles consecuencias ambientales del TLCAN. Por una parte, Jagdish Bhagwati (1993), un distinguido economista de la Universidad de Colombia, defendía "la hipótesis" de la curva ambiental de Kuznets, argumentando que el TLCAN aumentaría de manera progresiva el nivel de ingresos en México, hasta un punto en el cual la misma población ejercería presión al gobierno para proteger activamente al medio ambiente. Por otra parte, Herman Daly (1993), un economista ambiental que trabajaba entonces en el Banco Mundial, afirmaba que el tratado motivaría a las compañías estadounidenses contaminantes a trasladar sus operaciones a México, de esta manera abogando por "una hipótesis" de paraíso de la contaminación (pollution heaven). Empero, el punto principal del argumento de ambos economistas consistió en las consecuencias potenciales de la IED.

Los artículos que se refieren al medio ambiente fueron incluidos en el TLCAN como un compromiso para tranquilizar a varios grupos opuestos al tratado. De esta forma, en su preámbulo el tratado declara: “[...] los signatarios también decididos a [...] promover el desarrollo sostenible; reforzar la elaboración y la aplicación de leyes y reglamentos en materia ambiental". Asimismo, el medio ambiente se menciona en otros cuatro capítulos del TLCAN. Además, Canadá, Estados Unidos y México firmaron y ratificaron en 1993, antes del TLCAN, el Acuerdo de Cooperación Ambiental de América del Norte (ACAAN), el cual es visto por varios analistas políticos como una manera de asegurarse, por parte de Estados Unidos y Canadá, de que México se comprometería a desarrollar paulatinamente su capacidad institucional para la implementación eficaz de la protección al medio ambiente (Gallagher, 2004).

\section{Creación de nuevas instituciones ambientales}

El ACAAN representa un cambio real en los regímenes legales, políticos e institucionales que afectan la protección del medio ambiente y el comercio 
(Johnson y Beaulieu, 1996). Nunca antes las cuestiones ambientales habían estado tan visibles en una negociación comercial, ni tampoco habían resultado en la redacción de un documento adjunto a un tratado comercial. De hecho, desde entonces varios principios ambientales se han ido incluyendo en la mayoría de los tratados comerciales. Los artículos 14 y 15 del ACAAN conceden a firmas extranjeras y a individuos la capacidad de hacer una reclamación contra cualquier gobierno signatario del TLCAN que no respete el cumplimiento de la reglamentación ambiental encontrada en el acuerdo (Rugman, et al., 1999). Adicionalmente, el ACAAN también instituyó varias organizaciones, como la Comisión Norteamericana para la Cooperación Ambiental (CNCA o CCA), el Banco Norteamericano de Desarrollo (BND) y la Comisión de Cooperación Ambiental de la Frontera (CCAF).

La Comisión para la Cooperación Ambiental y la Comisión de Cooperación Ambiental de la Frontera tienen la facultad de evaluar proyectos ambientales con la finalidad de modernizar, por ejemplo, la infraestructura ambiental existente en México, y decidir si estos proyectos deben implementarse o no (Gilbreath, 2003). Si se decide a favor, dichos proyectos reciben un financiamiento por parte del Banco Norteamericano de Desarrollo, o de otros fondos destinados a estos objetivos. El BND anunció en 2009 que financiaba 129 proyectos en ese año, los cuales en su conjunto alcanzaban la cantidad de aproximadamente 980 millones de dólares. Lo anterior representa una inversión importante por parte del gobierno estadounidense, ya que, si bien ambos países contribuyen a financiar varias entidades creadas por el ACAAN, Estados Unidos, respondiendo a la presión de grupos ambientales durante las negociaciones de ACAAN, son por mucho la fuente de recursos financieros más importantes detrás del BND (Markell y Knox, 2003).

La CCA y la CCAF son también responsables de la organización de talleres de capacitación, de la organización de varios tipos de experiencias e investigaciones, de la publicación y propagación de los resultados de conferencias y simposios, así como de la organización de encuentros con actores políticos (Gilbreath, 2003). En suma, parece que Estados Unidos dedica una cantidad considerable de recursos humanos y financieros para participar en la construcción y el mejoramiento de la infraestructura ambiental de México, siempre y cuando vayan de acuerdo con sus requisitos particulares. 
Efectos de un nuevo marco institucional

El manejo estadounidense de las cuestiones ambientales es controvertido. Algunas voces de las más críticas acerca de la preservación ambiental afirman que los modelos económicos capitalistas modernos, en particular el régimen de libre comercio y su filosofía neoliberal, son en absoluto antitéticos a la preservación ambiental (Latouche, 2006; Shiva, 2002). En toda su diversidad, los movimientos ecológicos críticos favorecerían una disminución de la actividad industrial, un replanteamiento del concepto como la propiedad privada cuando se trata de recursos naturales, un reconocimiento de las consecuencias sociales de la destrucción ambiental, en particular para las mujeres y las poblaciones minoritarias, y darle prioridad al desarrollo humano y seguridad sobre los intereses de los inversionistas. Lejos de reconocer la existencia de estos puntos de vista, las instituciones ambientales que resultaron del TLCAN demuestran un compromiso fuerte con el concepto de liberalización económica y siguen una lógica de industrialización y crecimiento económico. Por lo tanto, el modelo ambiental definido como el más favorable para México es el que tiene que acomodar la protección del medio ambiente, el proyecto de libre comercio y los intereses de inversionistas extranjeros, supuestamente un vehículo importante del desarrollo económico de México.

Estas organizaciones diseminan ciertas normas, estándares y valores cuando participan en proyectos ambientales, y generalmente influencian el camino que México tiene que seguir para mejorar los niveles de protección del medio ambiente y simultáneamente aseguran que ciertos objetivos comerciales sean realizados. En el caso de México, esta dinámica es importante porque el Estado sólo comenzó hace poco a establecer su agenda ambiental y está ahora estableciendo su capacidad para regular el medio ambiente. La influencia de actores extranjeros, analistas y hacedores de políticas, principalmente estadounidenses que trabajan dentro de CAC o BND, sugiere que las normas ambientales que constituirán el marco institucional mexicano para tratar con la protección del medio ambiente serán generadas de manera externa al Estado mexicano. Esta situación reduce la autonomía de México para establecer su propia política ambiental y tocar cuestiones ambientales en el futuro, porque al nivel institucional el Estado funcionará dentro de un marco diseñado para proteger intereses privados, así como el ambiente natural.

Además, la existencia de estas organizaciones con propósitos ambientales en realidad puede beneficiar a inversionistas extranjeros, más que a México, 
por dos motivos. Primero, asumiendo que el marco ambiental está cada vez más influenciado por normas, reglas y políticas con una fuerte coloración estadounidense, este marco regulatorio se está volviendo más y más cercano al que se encuentra en Estados Unidos. Entonces, eso facilita la adaptación de los inversionistas estadounidenses al contexto mexicano. La teoría institucional estableció que los actores económicos familiares con las instituciones dentro de las cuales ellos tienen que funcionar, tienen una ventaja clara sobre otros actores (Goodin, 1996). Por lo tanto, se puede asumir que las MNC de Estados Unidos tendrían una ventaja sobre otras firmas extranjeras. Así, las normas y los procesos establecidos por CAC, BND y CCAF tienen consecuencias positivas para futuras operaciones de apertura de intereses comerciales estadounidenses en México.

Segundo, los inversionistas extranjeros se pueden beneficiar más directamente de la creación de estas organizaciones y sus inversiones al modernizar la infraestructura ambiental en México. Como se señaló anteriormente, la mayoría de los inversionistas extranjeros vienen de Estados Unidos y éstos están concentrados en una pequeña cantidad de multinacionales (Dussel Peters, 2008; Morales, 1999). Para adaptarse a las normas ambientales establecidas al nivel internacional, las firmas estadounidenses establecidas en México deben invertir fondos para respetar los estándares de contaminación, la eliminación de desperdicios, la salud y los procedimientos de seguridad. Cuando invierten en la infraestructura ambiental mexicana, las instituciones ambientales del TLCAN también contribuyen a la dotación de una mejor infraestructura para que operen las MNC ahorrándoles recursos. Por lo tanto, es posible afirmar que estas nuevas instituciones ambientales, al utilizar fondos estadounidenses, asisten a los inversionistas de Estados Unidos que operan en México a cumplir con las normas ambientales.

Para resumir esta sección, los debates que tuvieron lugar a principios de los años 1990 en cuanto a las consecuencias ambientales del TLCAN fueron parcialmente resueltos por la inclusión de cláusulas ambientales en el TLCAN y por la firma de un acuerdo específico, el ACAAN. Este acuerdo vio la creación de varias entidades que fueron diseñadas para asistir a México en reconciliar sus compromisos comerciales y sus obligaciones ambientales. Sin embargo, se puede analizar el marco institucional ambiental resultado de este proceso, como una manera de facilitar las actividades económicas de actores comerciales estadounidenses. Además, con la diseminación de normas específicas en cuanto a cuestiones ambientales, estas entidades institucionalizan un enten- 
dimiento específico y limitado de la importancia y de la manera de preservar los recursos naturales, un entendimiento que, de hecho, protege los intereses de los inversionistas extranjeros y confirma la supremacía de la ideología neoliberal del libre comercio. Al mismo tiempo, el TLCAN también contiene principios que impiden a los gobiernos adoptar medidas preventivas necesarias para proteger el medio ambiente, como se explica en la parte siguiente.

\section{TLCAN e inversión extranjera}

\section{El problema con el capítulo 11}

El TLCAN es un tratado comercial enfocado en la libre circulación de bienes y servicios, pero el tratado también promueve el flujo libre de inversiones en Norteamérica. En esta sección se pretende mostrar que la protección de IED asegurada por el capítulo 11 del TLCAN está en contradicción con potenciales estrategias nacionales relacionadas con cuestiones ambientales. Un caso particular, Metalclad versus México, lo utilizamos para demostrar este punto antes de destacar la importancia de este desarrollo para el marco institucional ambiental de México.

Una de los aspectos más polémicos del TLCAN es la sección que determina los derechos de los inversionistas. El amplio alcance del capítulo 11 no sería tan problemático sin las consecuencias implicadas por, entre otros, el artículo 1110 (Stone, 2003). Este artículo explica las prohibiciones de los gobiernos participantes del TLCAN acerca de la expropiación:

[...] ninguna de las Partes podrá nacionalizar ni expropiar directa o indirectamente una inversión de un inversionista de otra Parte en su territorio ni adoptar ninguna medida equivalente a la nacionalización o expropiación de esa inversión, salvo que sea:

a) Por causa de utilidad pública;

b) Sobre bases no discriminatorias;

c) Con apego al principio de legalidad y al artículo 1105 (1); y

d) mediante indemnización conforme a los párrafos 2 a 6 .

El artículo 1110 limita las acciones de los Estados miembros del TLCAN, mientras al mismo tiempo no queda claro cuáles serían las medidas que podrían ser concebidas como "equivalentes a la nacionalización o expropiación", y lo que podría ser entendido como las excepciones al artículo 1110. 
Además, si las reglas del capítulo 11 del TLCAN crean un marco seguro y previsible para el flujo de inversión dentro de Norteamérica (Soloway, 2000), permiten también a los inversionistas extranjeros traer sus quejas de expropiación contra el país anfitrión frente a un tribunal internacional, evitando los tribunales domésticos del país anfitrión (Aisbett, et al., 2006). Este tribunal, formalizado por el TLCAN, funciona conforme a las reglas del Centro Internacional para la Resolución de Disputas sobre Inversiones del Banco Mundial. El tribunal determinará entonces si la decisión tomada del país anfitrión puede ser entendida como "equivalente a la expropiación" y dará una sentencia obligatoria. La mayor parte de la controversia proviene del hecho de que "la expropiación o equivalente a la expropiación" no es definida en ninguna parte del tratado (Chiu, 2003).

Los comentaristas críticos del TLCAN sostienen que estos derechos dan amplios privilegios a los inversionistas extranjeros, sobre todo a las MNC, y debilitan la protección de los intereses públicos ambientales, entre otros (Moran, 2001). Estos derechos que protegen a los inversionistas también limitan la capacidad del Estado de promulgar una reglamentación ambiental más rigurosa por el temor a que eso podría significar pagar compensaciones enormes a estos inversionistas extranjeros. Si las preocupaciones ambientales son incluidas en otras partes del TLCAN y en el ACAAN, la aplicación concreta del artículo 1110 sugiere que las consideraciones ambientales llegan en segundo lugar después de la protección de los intereses de los inversionistas. El caso de Metalclad versus México ilustra esta proposición.

\section{Metalclad versus México}

En 1994, Metalclad, una corporación estadounidense especializada en procesar residuos tóxicos, adquirió una compañía mexicana que trata con la basura peligrosa y tóxica. Metalclad luego inició la construcción de un vertedero de desecho tóxico en Guadálcazar, un municipio de 28,000 personas en el estado de San Luis Potosí. A pesar de la oposición de la comunidad local acerca del vertedero y la falla de Metalclad en obtener el permiso de la municipalidad para construir en ese sitio, la construcción procedió (Carlsen y Salazar, 2002). Sin embargo, la oposición de las organizaciones ciudadanas, del gobierno estatal de San Luis Potosí, y de la administración municipal de Guadálcazar finalmente logró detener las operaciones de construcción en 1995. En el sep- 
tiembre de 1997 el gobernador de San Luis Potosí declaró que el sitio estaba ahora incluido en una zona ecológica protegida (Tamayo, 2001).

A continuación, Metalclad empezó una acción legal en contra del gobierno mexicano en conformidad con las cláusulas de protección del inversionista del artículo 1110 del capítulo 11 del TLCAN. Metalclad afirmó que la decisión de la administración municipal de Guadálcazar era equivalente a una expropiación (Chiu, 2003) y exigió 96 millones de dólares a México. En agosto de 2000 Metalclad ganó una decisión que concedió a la compañía un pago de 16.6 millones de dólares por parte del gobierno mexicano como compensación. México desafió la decisión del tribunal, alegando un error arbitral pero su petición sólo redujo la compensación que México tuvo que pagar a Metalclad a 15.6 millones de dólares (Chiu, 2003). Esta decisión sugiere que entre un daño potencial para la salud de la comunidad local y el interés financiero de una compañía extranjera privada, la administración municipal debiera haber dado la prioridad a los intereses de Metalclad y desatender la seguridad humana de la población.

\section{Significado para México}

El resultado del caso Metalclad versus México parece contradecir algunos de los esfuerzos de México para solucionar las cuestiones ambientales. Como se señaló anteriormente, la descentralización en cuanto a responsabilidades ambientales hacia gobiernos locales y estatales era un aspecto importante del intento de México de reforzar su sistema de regulaciones ambientales (Mumme y Lybecker, 2002). Sin embargo, cuando la administración municipal tomó medidas para preservar el medio ambiente en Guadálcazar, las reglas de protección de los inversionistas extranjeros se impusieron y confirmaron que los gobiernos locales o estatales en México no son actores legítimos para poner en práctica decisiones ambientales que conciernen a su comunidad. Eso sugiere que la descentralización de responsabilidades ambientales es realmente problemática en México cuando coincide con los planes de los inversionistas extranjeros.

La enmienda constitucional de 1998, que concedió a los ciudadanos mexicanos el derecho de disfrutar de un ambiente sano, está posiblemente también en contradicción con el capítulo 11 del TLCAN. En el caso Metalclad versus México, los expertos ambientales declararon que el suelo del sitio era muy inestable, a tal grado que los elementos tóxicos podrían infiltrarse en 
el subsuelo y entonces llevar la contaminación por todas partes a través de los mantos freáticos (Ojeda-Mestre, 2007). La construcción y la apertura de un vertedero de desecho tóxico en este sitio constituyeron, por lo tanto, una violación al derecho de los ciudadanos de disfrutar de un medio ambiente sano. Sin embargo, el tribunal desatendió este derecho inscrito en la Constitución mexicana y estimó que la protección del interés del inversionista extranjero debía permanecer incuestionable. De hecho, recompensada para no hacer caso de preocupaciones ambientales y desafiar el derecho de los ciudadanos locales, Metalclad recibió un pago importante del gobierno mexicano que podría haber sido usado en la construcción de vertederos seguros y legales muy necesarios en México (Carlsen y Salazar, 2002).

$\mathrm{Si}$, en el caso de Metalclad, la sociedad mexicana está en segundo lugar después de los intereses de los inversionistas extranjeros, de manera más general, los actores económicos domésticos también son discriminados por la aplicación del capítulo 11 (Chiu, 2003). La cláusula de expropiación del TLCAN ofrece un nivel de protección a los inversionistas extranjeros no disponible para los inversionistas domésticos. Únicamente los inversionistas extranjeros pueden usar el capítulo 11. Este resultado es irónico, cuando la prevención de la discriminación es uno de los aspectos principales de los tratados comerciales en la era de la mundialización (McGovern, 1995) e incluido en el mismo capítulo 11. Estas cláusulas aseguran que las firmas domésticas no pueden ser favorecidas comparativamente con los inversionistas extranjeros. El caso Metalclad versus México demuestra que los inversionistas extranjeros tienen derecho de hacer reclamaciones contra el gobierno mexicano bajo un tribunal internacional, al cual los inversionistas mexicanos no tienen acceso. De hecho, este arreglo representa una discriminación contra los inversionistas mexicanos. En otras palabras, el acuerdo de inversión sujeta al país anfitrión a riesgos legales que no encuentra con sus inversionistas nacionales (Aisbett, et al., 2006).

Finalmente, la protección de los intereses de los inversionistas extranjeros a través del capítulo 11 del TLCAN en el contexto de la relación asimétrica entre Estados Unidos y México, se vuelve un asunto político. En México los inversionistas extranjeros son masivamente estadounidenses (Dussel Peters, 2008) y por lo tanto las cláusulas relacionadas con la inversión, de facto protegen a los inversionistas estadounidenses. Con el TLCAN, la soberanía mexicana se encuentra limitada por la protección de los intereses, no de un estado de manera directa, pero sí de entidades comerciales privadas. Esta 
situación hace que el TLCAN sea de hecho un tratado que valida la autoridad privada de actores corporativos estadounidenses y amenaza la autoridad del Estado mexicano.

En suma, el capítulo 11 del TLCAN legalizó una concepción estadounidense de derechos a la propiedad, dio derechos a empresas extranjeras - discriminando las empresas nacionales-y fue usado para atacar una serie de regulaciones promovidas por el Estado para proteger bienes públicos sociales y ambientales (Kirton y MacLaren, 2002). El caso Metalclad versus México demostró que los inversionistas extranjeros son los beneficiarios reales del marco legal supranacional resultado del TLCAN. En la última sección se destacan los límites de los beneficios de la IED para México y la nueva dinámica en cuanto a la gobernanza ambiental global ilustrada por la integración económica norteamericana.

\section{IED y el medio ambiente en México: un matrimonio inquieto}

Beneficios ambientales de un aumento de la IED

A primera vista, el desarrollo de la reglamentación ambiental en México sugiere que la liberalización de la economía y de la IED desempeñó un papel positivo en atraer las cuestiones ambientales como prioridad en la lista de preocupaciones de los políticos mexicanos. Existe un consenso que explica que muchas de las medidas tomadas por el gobierno mexicano fueron motivadas por la perspectiva de un tratado comercial con Estados Unidos (Cameron y Tomlin, 2000; Mumme y Lybecker, 2002; Gilbreath, 2003; Gallagher, 2004). México preventivamente desarrolló y puso en práctica varias políticas ambientales a principios de los años 1990 para responder a las preocupaciones estadounidenses acerca del hecho de que el TLCAN iba a dar un incentivo a compañías domésticas de mover sus operaciones a México con el fin de beneficiarse de una reglamentación ambiental más laxa.

El ACAAN proporcionó a México recursos financieros, talleres y pláticas de capacitación para resolver asuntos ambientales (Deer y Esty, 2002). Las instituciones creadas pertenecen a un régimen ambiental más global, articulado aparentemente al proyecto de "desarrollo sostenible". Estas instituciones pretendieron conseguir mejores estándares de contaminación, desarrollar procesos de producción más limpios y modernizar la infraestructura ambiental - aunque sin preguntarse sobre el origen de la degradación ambiental que 
ocurre en México (Castro, 2004)—. La implementación del TLCAN aparece como un incentivo que animó y apoyó el gobierno mexicano en sus esfuerzos ambientales. Así, hay algunos que opinan que un efecto positivo de la IED que ha llegado México, es que ésta fue acompañada por el desarrollo de mejores normas, estándares y procesos ambientales.

Al mismo tiempo, en los noventa el régimen ambiental estaba madurando en Europa y en Estados Unidos, y entonces es posible que el gobierno mexicano también estaba respondiendo al mayor activismo ambiental en el país y en el entorno global (García Johnson, 2000). La fragilidad del ecosistema, así como el impacto de la contaminación sobre la salud son temas que los líderes políticos mexicanos hubieran podido considerar independientemente del TLCAN, debido a la presión popular y al coste económico que la contaminación del medio ambiente y la destrucción del ecosistema representan para la economía mexicana. Sin embargo, México podría haber elegido algunas medidas distintas de las que resultaron de la influencia estadounidense. La integración económica norteamericana, por lo tanto, proveyó a México con un marco particular para abordar cuestiones ambientales y eso puede haber impedido al país haber experimentar medidas alternativas para abordar estas cuestiones ambientales.

\section{Desarrollo contradictorio}

Como fue ilustrado previamente, algunos de los principios importantes del TLCAN, en particular en relación con las inversiones bajo el capítulo 11, no parecen ser congruentes con el desarrollo de un régimen ambiental global. Aunque la cuestión ambiental aparezca varias veces en el TLCAN, las instituciones legales que tienen autoridad para arbitrar disputas entre inversionistas extranjeros y los Estados partes del tratado validan la supremacía de los intereses de los inversionistas sobre preocupaciones ambientales (Chiu, 2003). De hecho, si inicialmente, el capítulo 11 quería proteger a los inversionistas extranjeros de futuras políticas de nacionalización, el capítulo 11 ha sido usado cada vez más para recuperar una disminución de ganancias debido a más reglamentación ambiental (Poirier, 2003). Las compañías extranjeras afirman ahora que la expropiación sucede cuando las inversiones son afectadas en su valor por culpa de unas políticas de protección del medio ambiente que fueron promulgadas después de que la inversión original fue hecha (Soloway, 2000). 
Por ejemplo, si México, debido a un cambio de gobierno, decidiera implementar reformas que podrían resultar en una disminución real del nivel de destrucción ambiental y de la contaminación, y así mejorar la salud de sus ciudadanos, el país sería acreedor a múltiples reclamaciones legales por parte de los inversionistas extranjeros. Estos inversionistas afirmarían correctamente que la modificación de la reglamentación ambiental les causa gastos y una pérdida de valor de su inversión. Los esfuerzos ambientales promulgados por México podrían ser fácilmente considerados equivalentes a una forma de expropiación. Entonces, no hay ningún incentivo para el gobierno mexicano de efectuar este tipo de acciones para proteger el medio ambiente si eso significa también planear el pago de cantidades de dinero enormes a estos inversionistas extranjeros.

Por una parte, la crisis ambiental requiere de medidas drásticas para por lo menos aminorar el impacto de la destrucción ambiental y de la contaminación. México está en el proceso de aumentar su capacidad nacional para tratar de resolver estas cuestiones ambientales. El Estado mexicano recibe, de forma indirecta, el apoyo de Estados Unidos en esta tarea a través de instituciones explícitamente creadas para mitigar los efectos de la industrialización y modernizar su infraestructura ambiental. Sin embargo, por otra parte las dinámicas de poder que resultan del marco legal emanado del TLCAN parecen aniquilar los resultados positivos del acuerdo complementario del tratado (ACAAN) y los esfuerzos ambientales autónomos de México.

Intereses protegidos por la IED y las instituciones ambientales

Millones de dólares estadounidenses son invertidos para apoyar a México a través de instituciones y proyectos ambientales, mientras al mismo tiempo Estados Unidos ha diseñado un tratado que favorece más los intereses de los inversionistas extranjeros sobre el medio ambiente de México. Esta contradicción aparente, en realidad se resuelve en la práctica considerando que los intereses estatales y privados son a veces compatibles o complementarios.

Como fue discutido anteriormente, las provisiones ambientales del TLCAN y las instituciones creadas por el ACAAN influencian las normas ambientales que son establecidas en México. Sin embargo, estas normas se originan en Estados Unidos. De hecho, esta situación dará a las firmas estadounidenses una ventaja institucional relativa en comparación con otros inversionistas extranjeros en México. Además, la modernización de la infraestructura 
ambiental mexicana también beneficia a las compañías estadounidenses, que pueden respetar normas ambientales sin que eso implique inversiones costosas para esas empresas. Por lo tanto, la ayuda económica estadounidense hacia México, en la construcción de su marco ambiental, beneficia en realidad a una gran parte de los intereses privados que se originan en Estados Unidos.

Hay entonces una cierta lógica en la protección de los intereses de los inversionistas extranjeros como está establecida por el capítulo 11 del TLCAN. Con la creación de un marco legal regional que garantiza la protección de los intereses de los inversionistas, el gobierno de Estados Unidos apoya a las corporaciones estadounidenses por segunda vez. No hay por consiguiente ninguna contradicción si uno entiende que está en el interés de Estados Unidos asegurarse de que México mejora su marco ambiental mientras sigue el modelo estadounidense; está también en su interés asegurarse que el capítulo 11 protege los intereses de los inversionistas estadounidenses.

\section{Autonomía reducida para México}

Finalmente, con base en este análisis, el impacto de la IED en México se puede entender de dos maneras. Primero, la dinámica país anfitrión-inversionista refuerza la relación de dependencia que México ha desarrollado respecto de Estados Unidos. A pesar de ser la onceava economía más grande en el mundo, México no tiene la capacidad financiera para invertir masivamente en la protección del medio ambiente. Por el acuerdo de lado del TLCAN, México recibe un apoyo financiero y técnico importante (Gilbreath, 2003). El gobierno mexicano podría dedicar entonces más recursos a otras áreas como salud o reformas de educación, por ejemplo. Sin embargo, para seguirse beneficiando de esta fuente de recursos financieros, México tiene que actuar de conformidad con las reglas que protegen los intereses económicos de los inversionistas extranjeros en su territorio. Materialmente, México ha aumentado su dependencia respecto a Estados Unidos para financiar sus proyectos ambientales.

La implicación de Estados Unidos en la construcción del marco institucional ambiental de México también significa que es un actor extranjero que disemina normas específicas e ideas sobre cómo manejar y resolver cuestiones ambientales. Este proceso tiene una influencia en los medios políticos mexicanos, que se vuelven cada vez más proclives a aceptar que estas normas e ideas son intrínsecamente buenas. Indirectamente, Estados Unidos participa por lo tanto en el marco regulador que se está diseñando en México, país que 
se ha vuelto dependiente de una fuente particular de ideas para dar sentido a sus esfuerzos ambientales.

Segundo, el marco legal que se desarrolló para regular y proteger a la IED ilustra cómo el bienestar ambiental de la sociedad mexicana importa menos que los intereses de los inversionistas extranjeros, a pesar del discurso ambiental que acompañó el TLCAN. Hay mucha divergencia y controversia sobre los beneficios potenciales de la IED y de la liberalización de la economía para México en términos de creación de empleos, reducción de desigualdades de ingresos, consideraciones ambientales o transferencia de tecnología y conocimiento (Morales, 1999; Dussel Peters, 2000; Gallagher y Zarsky, 2007; Ramírez, 2006). Sin embargo, el hecho de que las compañías extranjeras aumentaron constantemente sus inversiones en México desde que éste comenzó a liberalizar su economía, sugiere que hay un incentivo económico fuerte para ellas para hacer este tipo de inversión. Si los beneficios de la IED para la sociedad mexicana son, a lo más, discutibles, los beneficios para las entidades económicas extranjeras privadas están sin duda confirmados.

Además, la IED sirve como un modelo económico orientado a la exportación, mientras el costo ambiental está siendo pagado por la sociedad mexicana. Independientemente de que existan procesos de producción más limpios, es la sociedad mexicana quien en última instancia soporta la destrucción ambiental y la contaminación. Dicho simplemente, los bienes producidos por inversionistas extranjeros son exportados, y las ganancias realizadas terminan en manos de los accionistas de estas compañías extranjeras.

En suma, la adopción de un modelo económico neoliberal y la apertura de su economía a la inversión extranjera ha tenido resultados problemáticos para México en cuanto a la protección del medio ambiente. Si se observan los esfuerzos para mejorar la situación ambiental en México, eso pasa por la intrusión de Estados Unidos en la soberanía mexicana, manejando sus recursos naturales y el modo en que se supone debería manejar cuestiones ambientales. Por consiguiente el Estado mexicano, como consecuencia de la IED, no sólo perdió un poco de autonomía en relación con la preservación del medio ambiente, sino que también se hizo económicamente dependiente de un sistema que en última instancia beneficia más a actores extranjeros privados que a la sociedad mexicana. 


\section{Conclusión}

En este artículo se intentó ilustrar las contradicciones irreconciliables entre las preocupaciones ambientales y la protección de los inversionistas extranjeros en México. El manejo de la cuestión ambiental en la región de Norteamérica refleja la dinámica de poder que funciona entre Estados Unidos y México. Si la apreciación de que estamos frente a una crisis ecológica gana cada día más voz a nivel global, México se encuentra en una situación complicada debido al desequilibrio económico (y ahora legal) entre Estados Unidos y México.

Mientras el Estado mexicano intentó implementar una nueva reglamentación y un marco ambiental más adecuado, éste ha sido socavado en sus esfuerzos por la sobreimposición de reglas emanadas del régimen de libre comercio y de sus principios a propósito de cuestiones de inversión. Más que una fusión exitosa entre el régimen ambiental y el de libre comercio, la forma de gobernanza ambiental en México se dejó sojuzgar por los intereses de entidades económicas extranjeras. Esta situación no ha permitido a México diseñar su propio marco institucional con la autonomía necesaria para poder construir su capacidad reguladora ambiental.

Finalmente, cualquier actividad económica es importante cuando conlleva beneficios para la sociedad. La IED en México no parece desempeñar tal papel. Al contrario, como consecuencia de un aumento de la IED, la sociedad mexicana atestigua la reducción de recursos naturales y la contaminación de su ambiente natural sin recibir siquiera los beneficios económicos que resultan de estos modelos destructivos. Los inversionistas extranjeros, por su parte, se ven recompensados por desatender el derecho de ciudadanos mexicanos a un ambiente sano, dado el marco legal supranacional que establece el TLCAN. Una perspectiva ambiental en los mecanismos de la IED en México destaca la incompatibilidad de un régimen de libre comercio y el bienestar ambiental de la sociedad mexicana.

\section{Referencias bibliográficas}

Aisbett, E., L. S. Karp, y C. McAusland, Regulatory takings and environmental regulation in NAFTA's Chapter 11, 2006. Disponible en SSRN: http://ssrn. com/abstract=886168. Consulta: 25 de octubre de 2009. 
Álvarez Larrauri, R., e I. Fogel, "Environmental audits as a policy of state: 10 years of experience in Mexico", Journal of Cleaner Production, vol. 16, núm. 1, 2008, pp. 66-74.

Babb, S., Managing Mexico, Economists from Nationalism to Neoliberalism, Princeton University Press, Princeton y Oxford, 2001.

Bengoa, M., y B. Sánchez Robles, "Foreign direct investment, economic freedom and growth: New evidence from Latin America", European Journal Political Economy, vol. 19, núm. 3, 2003, pp. 529-545.

Bhagwati, J., "The case for Free Trade", Scientific American, núm. 269, noviembre, 1993, pp. 42-49.

Borja Tamayo, A., "The new federalism in Mexico and foreign economic policy: An alternative two-level game analysis of the Metalclad case", Latin American Politics and Society, vol. 43, núm. 4, 2001, pp. 67-90.

Box-Steffensmeier, J. M., L. W. Arnold, y C. J. W. Zorn, "The strategic timing of position taking in Congress: A study of the North American Free Trade Agreement", The American Political Science Review, vol. 91, núm. 2, 1997, pp. 324-338.

Cameron, M. A., y B. W. Tomlin, The Making of NAFTA, How the Deal Was Done, Cornell University Press, Ithaca y Londres, 2000.

Camp, R. A., Politics in Mexico, the Democratic Consolidation, $5^{\text {a }}$ edición, Oxford University Press, Nueva York y Oxford, 2007.

Carlsen, L., y H. Salazar "Limits to cooperation: A Mexican perspective on the NAFTA's environmental side agreement and institutions", en C. Deere y D. C. Esty (eds.), Greening the Americas, NAFTA's Lessons for Hemispheric Trade, MIT Press, Sabon, 2002, pp. 221-246.

Castro, C. J., "Sustainable development, mainstream and critical perspectives", Organization and Environment, vol. 17, núm. 2, 2004, pp. 195-225.

Chiu, C., "Chapter 11 and the environment', Environmental Policy and Law, vol. 33, núm. 2, 2003, pp. 71-75.

Cockroft, D. J., Mexico, Class Formation, Capital Accumulation, and the State, Monthly Review Press, Nueva York, 1983.

Daly, H. E., "The Perils of Free Trade", Scientific American, núm. 269, noviembre, 1993, pp. 50-57.

-—, Ecological Economics and Sustainable Development, Edward Elgar Publishing Limited, Cheltenham, 2007.

Deere, C., y D. C. Esty (eds.), Greening the Americas, NAFTA's Lessons for Hemispheric Trade, MIT Press, Sabon, 2002. 
Dussel Peters, E., "From export-oriented to import-oriented industrialization: Changes in Mexico's manufacturing sector, 1988-1994", en G. Otero (ed.), Neoliberalism Revisited. Economic Restructuring and Mexico's Political Future, Westview Press, Boulder, 1996, pp. 63-84.

- - Polarizing Mexico, The Impact of Liberalization Strategy, Lynne Rienner Publishers, Boulder y Londres, 2000.

- - "The impact of foreign direct investment in Mexico", Working Group on Development and Environment in the Americas, 2008. http://ase.tufts.edu/ gdae/WGOverview.htm. Consulta: octubre 29 de 2009.

Falkner, R., "American hegemony and the global environment", International Studies Review, vol. 7, núm. 4, 2005, pp. 585-599.

- - Business Power and Conflict in International Environmental Politics, Palgrave MacMillan, Hampshire, 2008.

Gallagher, K. P., Free Trade and the Environment: Mexico, NAFTA and beyond, Stanford University Press, Palo Alto, 2004.

Gallagher, K. P., y L. Zarsky, The Enclave Economy, Foreign Investment and Sustainable Development in Mexico's Silicon Valley, MIT Press, Cambridge y Londres, 2007.

García Johnson, R., Exporting Environmentalism, U.S. Multinational Chemical Corporations in Brazil and Mexico, The MIT Press, Cambridge, 2000.

Gilbreath, J., Environment and Development in Mexico, Recommendations for Reconciliations, Centre for Strategic and International Studies, Washington, DC, 2003.

Goodin, Robert E. (ed.), The Theory of Institutional Design, Cambridge University Press, Cambridge, 1996.

Ibarra Colado, E., "The Ethics of Globalization”, en S. Clegg y C. Rhodes (eds.), Management Ethics, Contemporary Contexts, Routledge, Londres y Nueva York, 2006, pp. 32-55.

Johnson, P. M., y A. Beaulieu, The Environment and NAFTA: Understanding and Implementing the New Continental Law, Island Press, Washington, DC, 1996.

Jones, G. A., y P. M. Ward, "Privatizing the Commons, reforming the Ejido and urban development in Mexico", International Journal of Urban and Regional Research, vol. 22, núm. 1, 1998, pp. 76-93.

Kirton, J., y V. MacLaren (eds.), Linking Trade, Environment and Social Cohesion: NAFTA Experiences, Global Challenges, Aldershot, Ashgate, 2002. 
Knight, Alan, "The Politics of Expropriation", en J. C. Brown y A. Knight (eds.), The Mexican Petroleum Industry in the Twentieth Century, The University of Texas Press, Austin, 1992, pp. 90-129.

Latouche, S., "The Globe Dowshifted", Le Monde Diplomatique, 2006. http:// mondediplo.com/2006/01/13degrowth. Consulta: 15 de octubre de 2009.

Looney, R. E., Economic policymaking in Mexico, Factors Underlying the 1982 Crisis, Duke University Press, Durham, NC, 1985.

Markell, D. L., y J. H. Knox, Greening NAFTA, The North American Commission for Environmental Cooperation, Stanford University Press, Stanford, 2003.

Máttar, J., J. C. Moreno Brid, y W. Peres, Foreign Investment in Mexico after Economic Reform, Serie Estudios y Perspectivas, núm. 10, CEPAL/United Nations Publications, 2002.

McGovern, E., International Trade Regulations, Globefield Press, Exeter, 1995. Morales, I., "NAFTA: The institutionalisation of economic openness and the configuration of Mexican geo-economic spaces", Third World Quarterly, vol. 20, núm. 5, 1999, pp. 971-993.

Moran, T. H., Parental Supervision, the New Paradigm for Foreign Direct Investment and Development, Institute for International Economics, Washington, DC, 2001.

Moreno Grid, J. C., J. Santamaría, y J. C. Rivas Valdivia, "Industrialization and economic growth in Mexico after NAFTA: The road travelled", Development and Change, vol. 36, núm. 6, 2005, pp. 1095-1119.

Mumme, S. P., "Enforcing international environmental agreements: Lessons from the U.S.-Mexico border", Journal of Environment \& Development, vol. 3, núm. 1, 1994, pp. 71-89.

Mumme, S. P., y D. Lybecker, "Environmental capacity in Mexico, an assessment”, en H. Weidner, J. Martin y H. Jörgens (eds.), Capacity Building in National Environmental Policy, a Comparative Study of 17 Countries, Springer, Berlín, 2002, pp. 311-329.

Ojeda Mestre, R., "Environmental justice in Mexico, hopes and disappointments", Environmental Policy and Law, vol. 37, núm. 2-3, 2007, pp. 142-157.

Otero, G., "Mexico's political future(s) in a globalizing world economy", The Canadian Review of Sociology and Anthropology, vol. 32, núm. 3, 1995, pp. 315-339. 
Poirier, M. R., "The NAFTA Chapter 11 expropriation debate through the eyes of a property theorist", Environmental Law, vol. 33, núm. 4, 2003, pp. 851-928.

Polanyi, K., The Great Transformation, $2^{\text {a }}$ edición, Beacon Press, Boston, 2001 (1944).

Quadri de la Torre, G., "Una breve crónica del ecologismo en México”, Ciencias, núm. 4 (número especial), 1990, pp. 56-64.

Ramirez, M. D., "Is foreign direct investment beneficial for Mexico? An empirical analysis, 1960-2001", World Development, vol. 34, núm. 5, 2006, pp. 802-817.

Rodrik, D., "The limits of trade policy reform in developing countries", Journal of Economic Perspectives, vol. 6, núm. 1, 1992, pp. 87-105.

Roett, R., y G. Paz, "The politics of institutional reform in Mexico and Latin America”, en R. Roett (ed.), The Challenge of Institutional Reform in Mexico, Lynne Rienner Publishers, Boulder, 1995, pp. 183-187.

Rugman, A., J. Kirton, y J. Soloway, Environmental Regulations and Corporate Strategy: A NAFTA Perspective, Oxford University Press, Oxford, 1999.

Shiva, V., Water Wars: Privatization, Pollution, and Profit, South End Press, Cambridge, 2002.

Soloway, J., "Environmental regulation as expropriation: The Case of NAFTA's Chapter 11”, Canadian Business Law Journal, vol. 33, núm. 1, 2000, pp. 92-127.

Stern, D., "The effect of NAFTA on energy and environmental efficiency in Mexico", Policy Studies Journal, vol. 35, núm. 2, 2007, pp. 291-322.

Stone, M., "NAFTA's Article 1110, environmental friend or foe?", Georgetown International Environmental Law Review, vol. 15, verano, 2003.

UNCTAD, World Investment Report, UNCTAD, Ginebra, 2002.

Waldkirch, A., "The effects of foreign direct investment in Mexico since NAFTA", MPRA Paper, núm. 7975, University Library of Munich, Germany, 2008.

Wisner, P. S., y M. J. Epstein, "'Push" and "Pull" impacts of NAFTA on environmental responsiveness and performance in Mexican industry", Management International Review, vol. 45, núm. 3, 2005, pp. 237-347. 


\section{Relaciones México-Japón}

Melba Falck Reyes

Héctor Palacios

\section{El japonés que conquistó Guadalajara}

La historia de Juan de Páez en la Guadalajara del siglo xVII

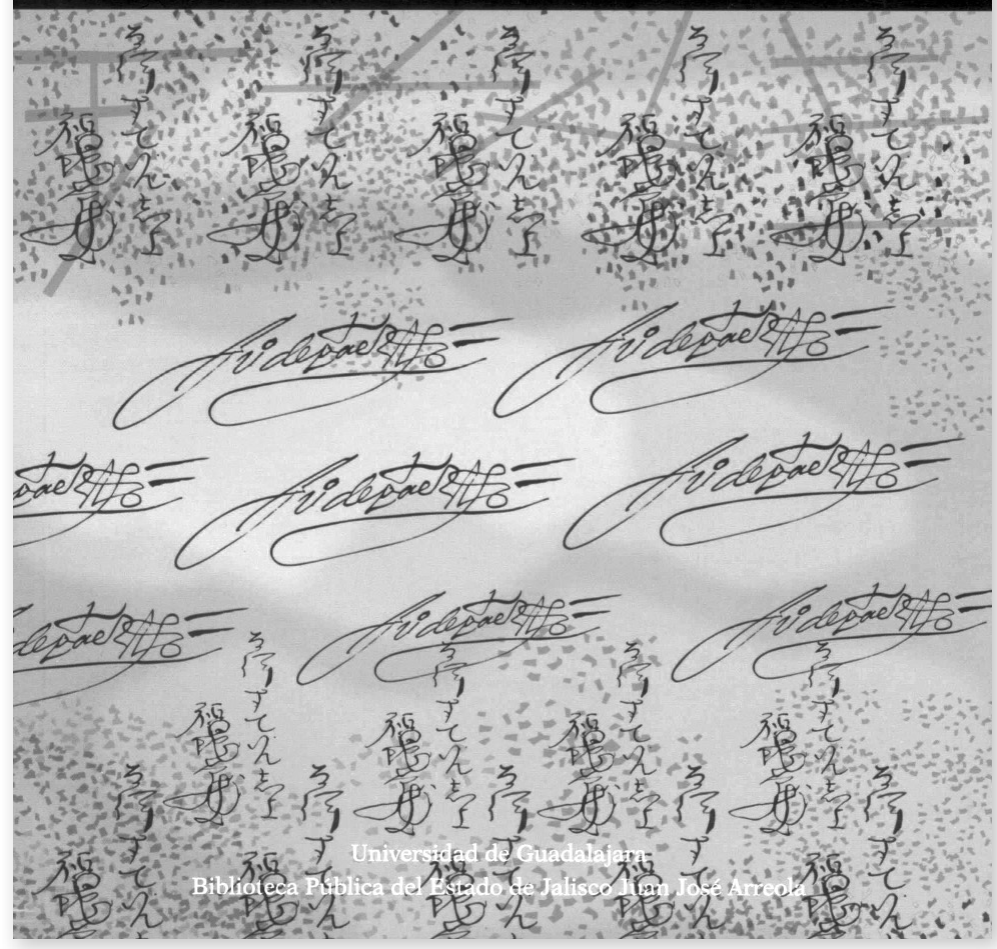

